\title{
Endoscopic management of esophageal perforation caused by calibrating bougie during laparoscopic sleeve gastrectomy
}

\author{
Gennaro Martines, Rosa Digennaro, Michele De Fazio, Palma Capuano \\ Department of Emergency and Organ Transplantation, University of Bari, Italy
}

Received: November 7, 2016

Accepted: February 28, 2017

Online Published: March 8, 2017

DOI: $10.5430 /$ css.v3n2p13

URL: https://doi.org/10.5430/css.v3n2p13

\begin{abstract}
Background: Laparoscopic Sleeve Gastrectomy (LSG) is one of the most used surgical techniques for the treatment of morbid obesity. The esophageal perforation (EP) secondary to the use of calibrating bougie is a rare complication.

Case presentation: A 43-year-old woman with a body mass index (BMI) of $54 \mathrm{~kg} / \mathrm{m}^{2}$ underwent LSG. During the use of a calibrating bougie, a distal EP occurred, but it became evident only during the second day after the surgery. The patient was hospitalized in Intensive Care Unit because of respiratory failure and her clinical conditions did not permit a safe surgical treatment. The EP was treated successfully by endoscopic conservative approach with a double-covered self-expanding endoprosthesis (SEMS).

Results: The esophageal calibrating bougie, often placed by an anaesthesiologist, is undoubtedly useful during the learning curve of the surgeon to ensure a correct sleeve size; however, it may result in severe and difficult-to-treat iatrogenic lesions.

Conclusions: Managing the complications through conservative endoscopy is possible, but in order to support these patients, the immediate availability of an intensive care unit is essential. We underline the importance of a dedicated team of surgeons and anaesthesiologists and a multidisciplinary team to treat major complications in bariatric surgery.
\end{abstract}

Key Words: Sleeve gastrectomy, Esophageal perforation, Bougie, Self-expanding endoprosthesis

\section{INTRODUCTION}

Laparoscopic Sleeve Gastrectomy (LSG) is an effective surgical technique to treat primary morbid obesity, also in superobese patients. Although literature data show that the gastric bypass guarantees a better weight loss after one-year followup, sleeve gastrectomy remains an ideal bariatric procedure because it is simple and it avoids digestive anastomosis or bypass and their long-term complications. ${ }^{[1]}$ Furthermore, in case of insufficient weight loss, a second-stage operation, such as re-sleeve gastrectomy or gastric bypass, can be pro- posed.

The most common major complications of sleeve gastrectomy described in literature are leakage $(6.5 \%)$, bleeding $(2 \%)$, stenosis $(0.6 \%)$ and the development of gastroesophageal reflux $(6 \%) .{ }^{[2]}$

As recommended by the International Sleeve Gastrectomy Expert Panel Consensus Statement, sleeve sizing is commonly performed with the placement of a bougie, in order to protect the patient from excessive gastrectomy and stenosis. Thirty-six-Fr bougies are the most commonly used. ${ }^{[3]}$

\footnotetext{
*Correspondence: Gennaro Martines; Email: gerrymartines@ virgilio.it; Address: Department of Emergency and Organ Transplantation, University of Bari, Italy.
} 
Conversely, the use of intraoperative endoscopy for the calibration of the stomach has sparsely been reported. ${ }^{[4]}$

The calibration with bougie during LSG is rarely related to complications. ${ }^{[5]}$ However, this technique can lead to complications such as accidental stapling across the tip, staple-line corkscrewing and esophageal perforation (EP). ${ }^{[6]}$

The EP remains a very rare complication, secondary to the use of esophageal calibrating bougie, generally operated by the anesthesia team. As reported in literature, this adverse event generally requires a surgical treatment. ${ }^{[7]}$ The EP can lead to dramatic sequelae during the immediate postoperative period, and the patient may not tolerate a major surgery.

We describe a minimally invasive management of a case of iatrogenic EP caused by a 36-Fr calibrating bougie in a super-obese patient who underwent LSG.

\section{Case presentation}

A 43-year-old woman with a BMI of $54 \mathrm{~kg} / \mathrm{m}^{2}$ underwent LSG. She had a medical history of high blood pressure, obstructive sleep apnea which required the use of continuous positive airway pressure (C-PAP) during sleep and diabetes mellitus treated with oral medications.

Surgery was performed with the standardized technique. During the gastric section, a 36-Fr bougie was used for calibration. The stomach section was realized with a linear stapler and the reinforcement of the suture with fibrin glue. Leak test with methylene blue was negative. No complication was evident during the surgery and in the first 24 hours after the operation.

In the second postoperative day the patient presented tachycardia, leukocytosis and a progressive respiratory failure condition with no specific signs of pneumothorax on the chest $x$-ray. The respiratory condition worsened after positive pressure ventilation (BiPAP). The patient was therefore transferred to the Intensive Care Unit (ICU) and intubated. Chest CT scan showed left pneumothorax associated with pleural effusion and subcutaneous emphysema (see Figure 1a). Control chest CT scan with Gastrografin detected an oral contrast leakage at the base of the left lung, suggesting a perforation at the level of the lower third of the esophagus (see Figure 1b). Considering the critical clinical condition, the patient was deemed unable to tolerate surgery. Hence, a less invasive approach was preferred, and the patient underwent esophagogastroduodenoscopy (EGD). The endoscopy confirmed a perforation of the distal esophageal wall. A double-covered self-expanding endoprosthesis (SEMS) was placed (see Figure 2). During the following days the patient 14 developed a spontaneous left hemothorax , related to the alteration of the coagulation caused by the sepsis; for this reason, a chest drain was placed. After the hemothorax resolved, the patient developed a pleural empyema which required a left postero-lateral thoracotomy and a double pleural drainage. Because of the onset of a severe acute respiratory distress syndrome (ARDS), the patient underwent Extra Corporeal Membrane Oxygenation (ECMO). The outcome of these procedures resulted in the resolution of the acute clinical condition.

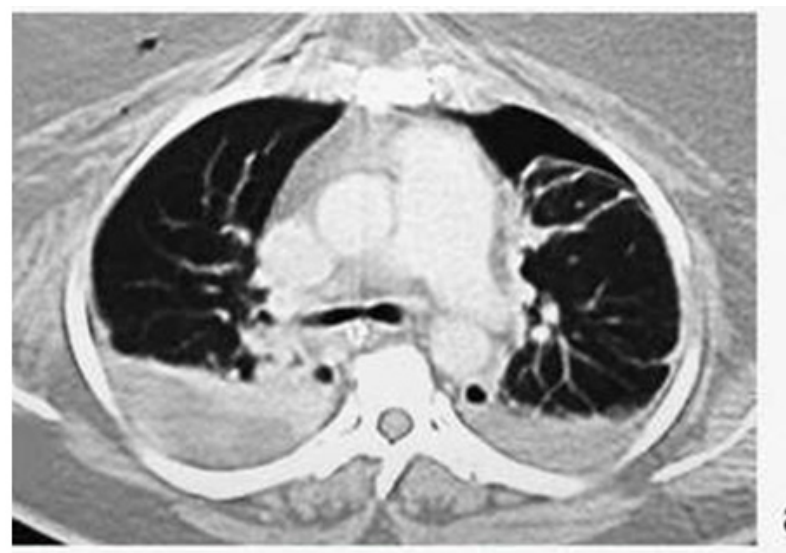

a

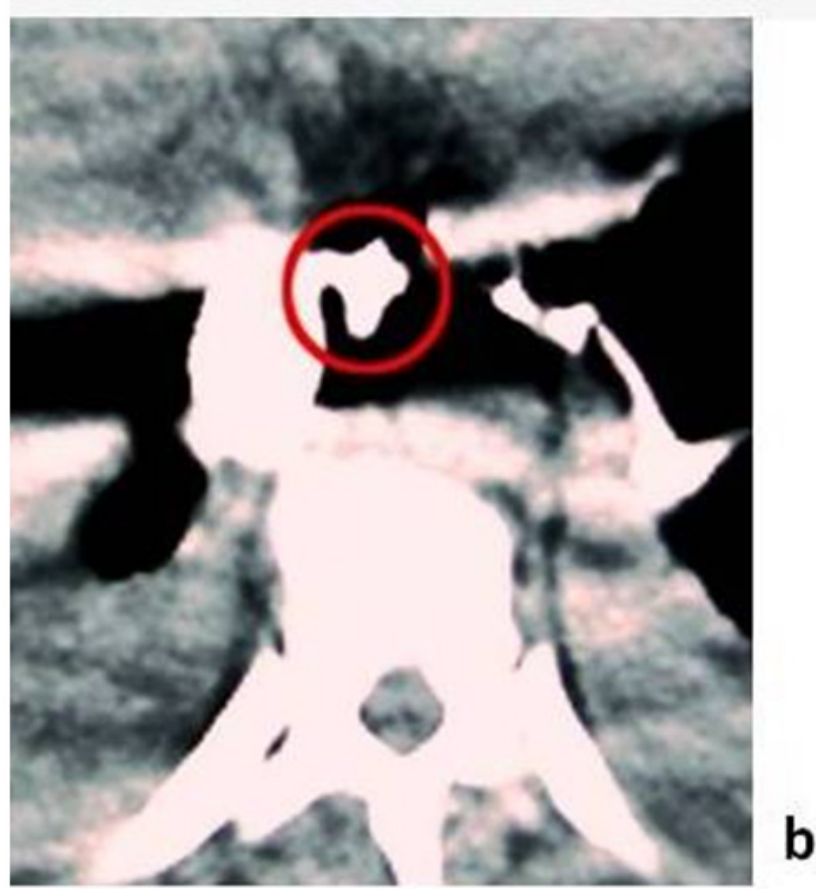

Figure 1. Chest CT scan

a) Chest CT scan in the second postoperative day: Left pneumothorax associated with pleural effusion and subcutaneous emphysema; b) Chest CT scan with Gastrografin: Esophagopleural fistula

All the $x$-ray and CT scans taken after the placement of the SEMS showed the complete resolution of the esophageal- 
pleural fistula. The SEMS was endoscopically removed without any complication after 8 weeks (see Figure 3 ). The clinical conditions of the patient are satisfactory after eighteen months of follow-up. There is no evidence of late complications. The excess weight loss (EWL) is $48.5 \%$.
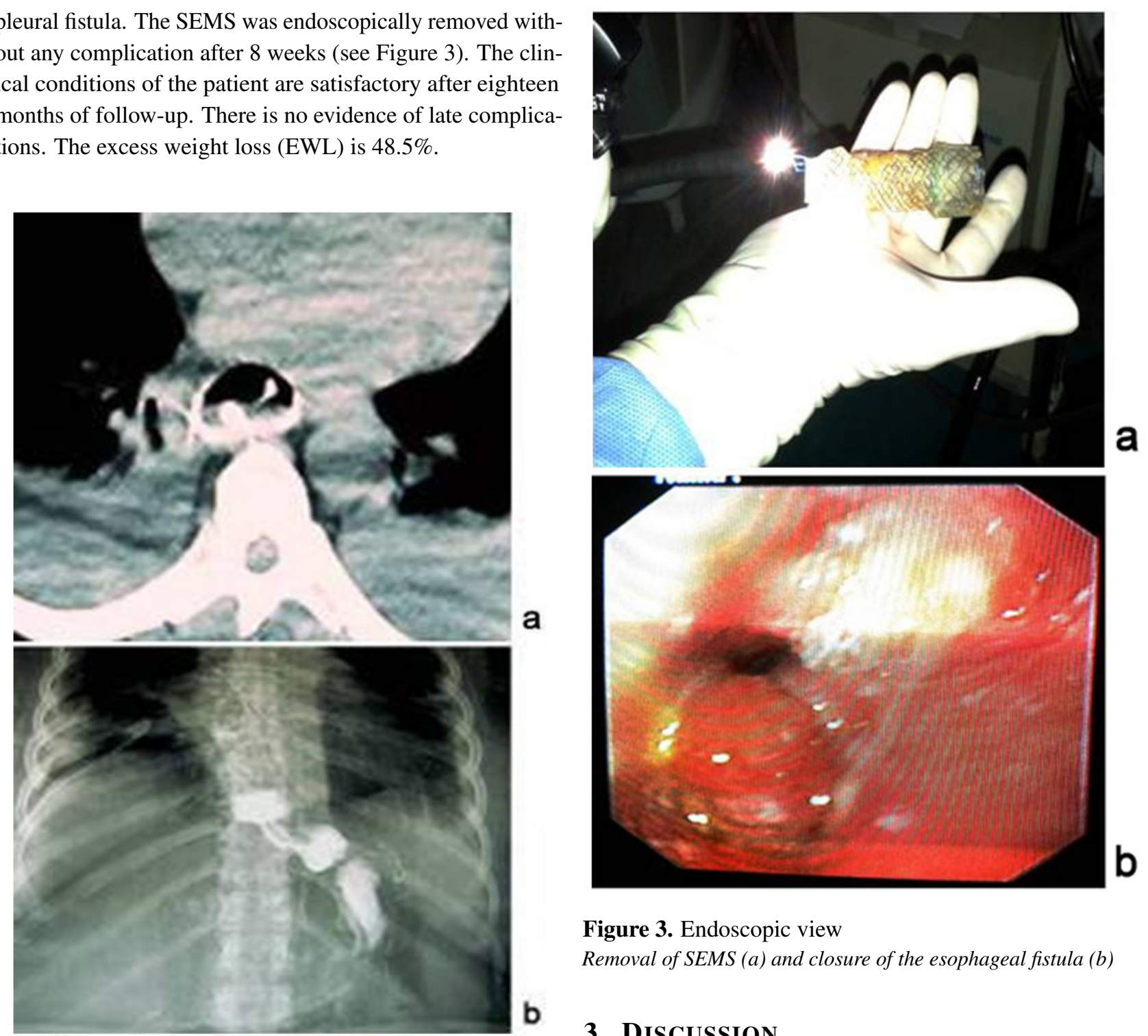

Figure 3. Endoscopic view

Removal of SEMS (a) and closure of the esophageal fistula (b)

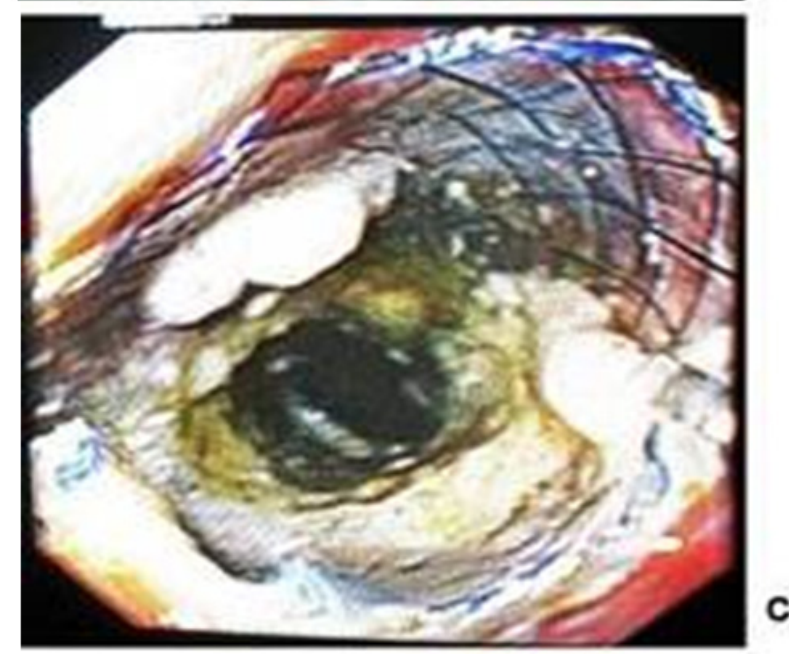

Figure 2. Correct position of double-covered SEMS a) CT scan control; b) Rx with hydrosoluble contrast medium; c) endoscopic view

\section{Discussion}

LSG is an easy-to-perform procedure, with a low incidence of complications. Sometimes these may occur with dramatic implications, especially in super-obese patients with high anesthesiological risk. During LSG, the esophageal calibrating bougie is of undoubted utility for the learning curve of the surgeon; ${ }^{[8]}$ it avoids potential strictures, but entails the risk of severe complications. LSG requires bougie movements to achieve optimal placement, gastric decompression, gastric sizing and leak test. In super-obese patients it is more difficult to place and visualize the intraluminal bougie; therefore, in such patients, the surgeon has to ask the anesthesiologist to move the bougie several times to confirm the placement. All these movements, along with the patient in reverse Trendelenburg position, may cause iatrogenic lesions. ${ }^{[6]}$

The professional in charge of positioning and moving the calibrating bougie must be aware of these risks. Hence, the importance of a team of surgeons and anesthesiologists. 
The EP, related to the use of the calibrating bougie, is a rare but life-threatening complication for the patient, and it is difficult and expensive to treat. ${ }^{[9]}$

In case of EP, although no guidelines currently exist, the choice of the correct management can be hard, depending on the location and the dimension of the perforation and on the patient's performance status. ${ }^{[10]}$

Various options, either surgical or non-surgical, can be considered. ${ }^{[11]}$

Regardless of the option chosen, a correct management includes bowel rest with use of total parenteral nutrition, appropriate antibiotic therapy, treatment of associated collections, pneumoperitoneum or pneumothorax. Even if rare, these complications often arise with critical clinical conditions. Hence, admission in an intensive care unit with resuscitation facilities, such as emergency airway equipment and respiratory support should be considered for such patients. ${ }^{[12]}$

Surgical treatment is an important option in many cases, but a non-operative approach should be preferred whenever the clinical situation permits a less invasive approach. ${ }^{[13]}$

Non-operative approaches include endoclipping or endoscopic stenting. Since iatrogenic upper gastrointestinal perforations are rarely observed, suggests the endoscopic treatment that should be preferred; most of the data regarding the effectiveness of the various closure techniques come from retrospective case series and retrospective studies. ${ }^{[14]}$ Endoclipping could be performed using both through-the-scope (TTS) or over-the-scope clips (OTS). As recently described in review by Verlaan et al., endoscopic repair with TTS has an overall success rate of $90.2 \%$ for perforations at various locations. ${ }^{[15]}$ Despite OTS has showed a technical success rate of $97.1 \%$, its clinical success has been described much lower $(70 \%)$ in recently published retrospective multicenter studies. $^{[16]}$

SEMS represent an effective alternative to endoclip therapy in case of EP with observed technical and clinical success rates of $91 \%$ and $81 \%$, respectively. ${ }^{[17]}$

The choice among these different endoscopic treatments depends on qualities of perforation (i.e. vergs, dimension) and availability of devices.

\section{Conclusions}

The present report remarks that the insertion of the bougie during LSG has to be performed by dedicated professionals, and that, whenever an anesthesiologist who is trained in bariatric surgery is not available, the insertion has to be made by a surgeon. Furthermore, it proves that endoscopic stents with a double-covered SEMS could permit the resolution of an esophageal fistula and could be appropriate in a patient who cannot tolerate further extensive surgery. Finally, it highlights the importance of a highly specialized multidisciplinary center, including a bariatric surgeon, an endoscopist and the availability of an intensive care unit for the management of these patients.

\section{CONFLICTS OF INTEREST Disclosure}

The authors declare they have no conflict of interest.

\section{REFERENCES}

[1] Schneck AS1, Stenard F, Iannelli A. Back to Sleeve: an Extreme Solution for Specific Complications of the Roux-en-Y Gastric Bypass.Obes Surg. 2015 Aug; 25(8): 1499-501. PMid: 26093631. https://doi .org/10.1007/s11695-015-1770-z

[2] Weiner RA, Weiner S, Pomhoff I, et al. Laparoscopic sleeve gastrectomy - influence of sleeve size and resected gastric volume. Obes Surg. 2007 Oct; 17 (10) : 1297-305. PMid: 18098398. https://doi.org/10.1007/s11695-007-9232-x

[3] Deitel M, Gagner M, Erickson AL, et al. Third international summit: current status of sleeve gastrectomy. Surg Obes Relat Dis Off J Am Soc Bariatr Surg. 2011; 7(6): 749-59. PMid: 21945699. https://doi.org/10.1016/j. soard.2011.07.017

[4] Andreas A, Adamantios M, Antonios A, et al. Laparoscopic Sleeve Gastrectomy for Morbid Obesity with Intra-operative Endoscopy: Lessons We Learned After 100 Consecutive Patients. OBES SURG. 2015; 25: 1223. PMid: 25502069. https://doi.org/10.1007/ s11695-014-1524-3

[5] Abu-Gazala S, Donchin Y, Keidar A. Nasogastric tube, temperature probe, and bougie stapling during bariatric surgery: a multicenter survey. Surg Obes Relat Dis. 2012; 8(5): 595-600. PMid: 21963196 https://doi.org/10.1016/j. soard.2011.08.017

[6] Gagner M, Huang RY. Comparison between orogastric tube/bougie and a suction calibration system for effects on operative duration, staple-line corkscrewing, and esophageal perforation during laparoscopic sleeve gastrectomy. Surgical Endoscopy. 2016; 30: 1648-1655. https://doi.org/10.1007/s00464-015-4399-z

[7] Theodorou D, Doulami G, Larentzakis A, et al. Bougie insertion: A common practice with underestimated dangers. International Journal of Surgery Case Reports. 2012; 3(2): 74. PMid: 22288051 https://doi.org/10.1016/j.ijscr.2011.08.017

[8] Rosenthal RJ. International Sleeve Gastrectomy Expert Panel. International Sleeve Gastrectomy Expert panel consensus statement: best practice guidelines based on experience of $>12,000$ cases. Surg Obes Relat Dis. 2012; 8(1): 8-19. PMid: 22248433. https : //doi.org/10.1016/j.soard.2011.10.019

[9] Oyasiji T, Lujic M, Suarez L, et al. Cost of treatment due to perforation, esophageal perforation: etiology, outcome and cost analysis over a decade in a community teaching hospital. Surg Endosc. 2012; 26(Suppl 1): 249-430. 
[10] Vallböhmer D, Hölscher AH, Hölscher M, et al. Options in the management of esophageal perforation: analysis over a 12-year period. Dis Esophagus. 2010 Apr; 23(3): 185-90. PMid: 19863642. https://doi.org/10.1111/j.1442-2050.2009.01017.x

[11] Gubler C, Bauerfeind P. Self-expandable stents for benign esophageal leakages and perforations: long-term single-center experience. Scand J Gastroenterol. 2014 Jan; 49(1): 23-9. PMid: 24164499. https: //doi.org/10.3109/00365521.2013.850735

[12] Goenka MK, Goenka U. Endotherapy of leaks and fistula. World Journal of Gastrointestinal Endoscopy. 2015; 7(7): 702-713. PMid: 26140097.

[13] Søreide JA, Viste A. Esophageal perforation: diagnostic work-up and clinical decision-making in the first 24 hours. Scandinavian Journal of Trauma, Resuscitation and Emergency Medicine. 2011; 19: 66. PMid: 22035338. https://doi.org/10.1186/1757-7241-19-66
[14] Schmidt A, Fuchs KH, Caca K, et al. The Endoscopic Treatment of Iatrogenic Gastrointestinal Perforation. Deutsches Ärzteblatt International. 2016; 113(8): 121-128. PMid: 26976712.

[15] Verlaan T, Voermans RP, Henegouwen MIVB. Endoscopic closure of acute perforations of the GI tract: a systematic review of the literature. Gastrointest Endosc. 2015; 82: 618-62. PMid: 26005015. https://doi.org/10.1016/j.gie.2015.03.1977

[16] Farnik H, Driller M, Kratt T, et al. Indication for "Over the Scope" (OTS)-Clip vs. covered self-expanding metal stent (cSEMS) is unequal in upper gastrointestinal leakage: results from a retrospective head-to-head comparison. Gastrointest Endosc. 2015; 10: 1-12. https://doi.org/10.1371/journal.pone. 0117483

[17] Dasari BVM, Neely D, Kennedy A, et al. The role of esophageal stents in the management of esophageal anastomotic leaks and benign esophageal perforations. Ann Surg. 2014; 259: 852-860. PMid: 24509201. https://doi.org/10.1097/SLA . 00000000000005 64 